\title{
Olaf Bulls dikt Metope - lest som terapeutisk samtale
}

\author{
Metope er et av de mest verdsatte diktene i norsk lyrikk. Diktet er et mesterlig spill med ord, vakre, konkrete \\ bilder og intense følelsesuttrykk. Ved første gjennomlesing er det lett å bli så overveldet av diktets skjønnhet \\ at man mister innholdet. Diktet er formet som en samtale mellom en mann og en kvinne. Samtalen kan, litt \\ overraskende, tjene som inspirasjonskilde for terapeuten som ønsker å bedre sin pasientkommunikasjon.
}

Njål Flem Mæland

nflem@online.no

Olaf Bull ble født i 1883 i Kristiania og døde bare 49 år gammel i 1933 (1). Opp gjennom 1900-tallet har han hatt en enestående status som inspirasjonskilde for norske diktere. I nordisk sammenheng blir han ofte nevnt som en av de fremste innen skandinavisk lyrikk (1).

Selv hadde han ikke et enkelt liv og slet med angst og depresjon. Han utviklet tidlig et alkoholproblem og var gjentatte ganger innlagt i sykehus. Vinteren 1925 forsøkte han å ta sitt eget liv. Han hadde knapt noe ordinært lønnet arbeid og slet hele livet med økonomiske problemer. Helt fra ungdommen av var han på stadig tiggerferd for å overleve fra dag til dag. På slutten av livet hadde han lammelser, leverskader og hallusinasjoner. Han døde på psykiatrisk avdeling ved Ullevål sykehus, sankthansaften 1933 (1).

Det er lett å se for seg at hans vanskelige liv fikk betydning for diktningen. Diktene vitner om en uvanlig sensibilitet, og følelsesregisteret spenner fra dyp avgrunn til overstrømmende livsfølelse. Viktige motiver er kjærligheten, døden, angsten, våren og kunsten.

\section{Metope}

Diktet Metope kom i diktsamlingen med samme navn i 1927. Det er skrevet til hans tredje kone, Susanne Dain (f. 1895), som han giftet seg med i 1925 (2). Diktet er formet som en samtale mellom dikteren - mannen - og hans elskede, en kvinne. Det består av tre deler. De første tre strofene er mannens, i form av hans tanker og en kort replikk. Deretter svarer hun i de fire neste strofene, før hans tanker avslutter diktet i den aller siste strofen. Diktet har altså form av en dialog, og det er dette aspektet jeg skal se nærmere på i denne artikkelen.

\section{Pan og Psyke}

Diktet starter med at mannen/dikteren ønsker å gjøre kvinnen evig gjennom å skape et diktverk.

«Dig vil jeg ømt i rytmer nagle fast! / Dig vil jeg dypt og blivende bevare / $i$ digtets evige, unge alabast.»

Han føler så etter hvert at det er noe i henne som er urolig, og i utakt med hans egen oppstemthet, og han spør hva hun tenker på. Hun svarer så i sine fire strofer med å gi uttrykk for dødsangst, og fortvilelsen over at det vakre de har sammen nå, ikke skal vare evig. Disse strofene er formet som en monolog. Hun viser her en veksling mellom

\section{«Diktene vitner om en uvanlig sensibilitet»}

å være helt til stede i det vakre øyeblikket i nåtiden, og desperat å fortvile over at det som er nå, skal ta slutt. Han svarer så i sin siste strofe med sorg over at han ikke kan nå helt inn til henne, samtidig som han søker å trøste henne ved å være fysisk nær.

Til slutt fremheves de to som Pan og Psyke. Uttrykkene er fra gresk mytolog og viser til gudene for blant annet henholdsvis begjær og menneskesjel. Han - som Pan står for begjær, mens hun - som Psyke - er den besjelede og fortvilte. Avslutningen kan slik gi et inntrykk av uforenlighet og motsetning. Om dette skriver for eksempel Jan Erik Vold: «Han lykkes i sine intensjoner - å skrive Norges beste dikt. Hun «mislykkes» i å bli fri sin dødsangst.» (3).

\section{Dialog mellom terapeut og pasient}

Jeg skal lese diktet på en annen måte, nærmest motsatt av tolkningen til Jan Erik Vold. Jeg skal se det som en dialog, som man kan tenke seg foregår mellom terapeuten (dikteren/mannen) og pasienten (kvinnen). Vi skal se at samtalen da kan leses som terapi.
Jeg starter med dikterens/mannens replikk i siste del av strofe tre. Han beskriver først den vakre kvelden rundt dem. Så blir han plutselig oppmerksom på henne.

«Gjennom ditt blik en varm og dyp beaandning - /midt i et mulm av blaat kan øiet faal et drivende stcenk, en fuktig glans af honning, / og stille spør jeg dig «Ven - hvad toenker du paa?»»

Det første som skjer her, er at han blir oppmerksom på noe ordløst. Han fanger opp et ikke-verbalt signal hos henne, «noe i øyet». Så blir han seg dette så bevisst at det bryter inn i hans skildring av skjønnheten omkring dem, han avslutter denne og vender oppmerksomheten mot henne. Han viser henne at han har oppfattet dette ikke-verbale signalet, og spør henne om hva hun tenker.

Dette kan høres banalt ut, men som vi skal se, er det ikke det. Det er krevende å fange emosjonelle signaler, bli dem bevisst, for så å vise samtalepartneren oppmerksomhet. I konsultasjonen handler det om å være oppmerksom på pasientens blikk, kroppsspråk, ansiktsuttrykk og stemmeleie.

Også verbale uttrykk kan vise til underliggende emosjoner. På engelsk brukes begrepet «clue», som kan oversettes med «hint». Vi kan definere slike hint som verbale og ikke-verbale uttrykk som antyder en underliggende, ubehagelig emosjon som ikke kommer klart til uttrykk. Dette er vanlig i konsultasjoner. Levinson og medarbeidere finner at lege-pasient-samtaler inneholder hint i mer enn halvparten av samtalene, med et snittantall på 2,6 i primærhelsetjenesten og 1,9 i sykehuspraksis (4). Dessverre er legene dårligere enn dikteren i diktet til å fange opp disse. Zimmermann og medarbeidere viser i en systematisk oversikt at leger mister de fleste av pasientens hint (5). Spesielt er det vanskelig for legen å fange opp mer skjulte ikke-verbale hint, av den typen vi ser nettopp i Metope (6). Det er viktig å fange opp pasientens underliggende emosjoner. Levinson og medarbeidere viser at det å fange opp hint faktisk forkorter konsultasjonens varighet (4). Levinson konklu- 
Dig vil jeg ømt i rytmer nagle fast!

Dig vil jeg dypt og blivende bevare i digtets evige, unge alabast!

Du solbevægede sværmerske! Med panden pikelig vendt mod kveldens bleke guld, vender du mildt en himmel mot en annen, likesaa lys og øm og løndomsfuld! Gjerne ga jeg min verdens vers tilhope, hadde jeg magt til ét: at hugge ind i mindets trodsige sten en myk metope over dit vare, omridsømme sind!

Vi vandrer i fugtig fjæresand! Du lytter til sommersjøens luftige bølgesprut! Vi føler det fromt, at kveldens stilhet flytter sin tonende grændse altid længer ut! Det kimer af falmet lyd, som glir tilbake bak rødmende lunde, gyldne kirkespir og luftens lysende bølger synker svake, som bækker af sol fra bjærgene, som blir!

Aaserne blaane. Stjernerne er nære! De siste skyer skynder sig hjem tilkvelds! Engen har andagt - op af luftens fjære stiger Arcturus! Lindt, bag graastensgjærdet, aander en vind i rugens sølvgraa pels! Gjennem dit blik en varm og dyb beaandning midt $i$ et mulm af blaat kan øiet faa et drivende stænk, en fugtig glans af honning, og stille spør jeg dig "Ven - hvad tænker du paa?"

"Jeg tænker paa kvelder som denne, jeg ikke faa lov til at leve -

paa modne marker, som bruser af korn, uten mig! Paa rørende, lette smaating: Aks, som knækkes, veier i sjøen, bleke seil derute, bølger, som strømmer mot stranden uten mig! Hverdagen, ven, som mildt blir ved bak graven, tænker jeg paa, og alle de dype, blaa, kommende kvelder her i sommerhaven, uten mit sind mot dit, tænker jeg paa!
Det hele fylder mit øie som en taare, jeg, ensom og angst og arm, skal graate snart! Alle de ting, som nu ikveld er vore -om faa, berusende aar staar stunden fore, da taakerne glir, og øiet kan se klart! Aa, elskede, se hvor dyb og sort en fjære! Saa underlig stranden blev, da vandet faldt! Mon rædslens kveld er fjærn, da vi skal være en styggere strand end dén, forladt af alt?

Allikevel er det et sødt og saligt under, at engene her, med korn og krat og trær, og bjærgene bak, saa dybt som blikket bunder, dugges saa sødt af vore smaa sekunder -bare den bjærken dér, hvor vor den er! Og skigarden da! Den gamle redskabsvognen ligger i græsset støt og stadig staar de svære hesjestængerne op i rognen, og grøften er grøn som før, i alle aar!

Aa, ven, lot gravenes dyp sig vildt besværge, vilde jeg bli til vangen her, med hø, til bjærken dér, med stjerner i, og bjærget, bare for slik, paa annen vis, at værge den hellige haven vor, for dét: at dø -- ! Ta om mig, ven, og hold mig! Saan at trykkes er snart det eneste glimt af haab, jeg vét den hastige, hete straalestund, det lykkes at vække i mig en annen evighet!"

Og jeg, en levende mand, paa jorden hjemme, en tydelig mand af kjød, fra taa til top, kan, svimmel og sky, i favnen min fornemme noget, som bare er blik og sind og stemme, i smertelig angst og anelse løst op! Du ensomme! Alt, jeg kan, er stumt at stryke dit duftige haar, med haanden din i min og øie til øie saan, staar Pan og Psyke foran et hav af korn, i stjerneskin!

Olaf Bull (1883-1933) 


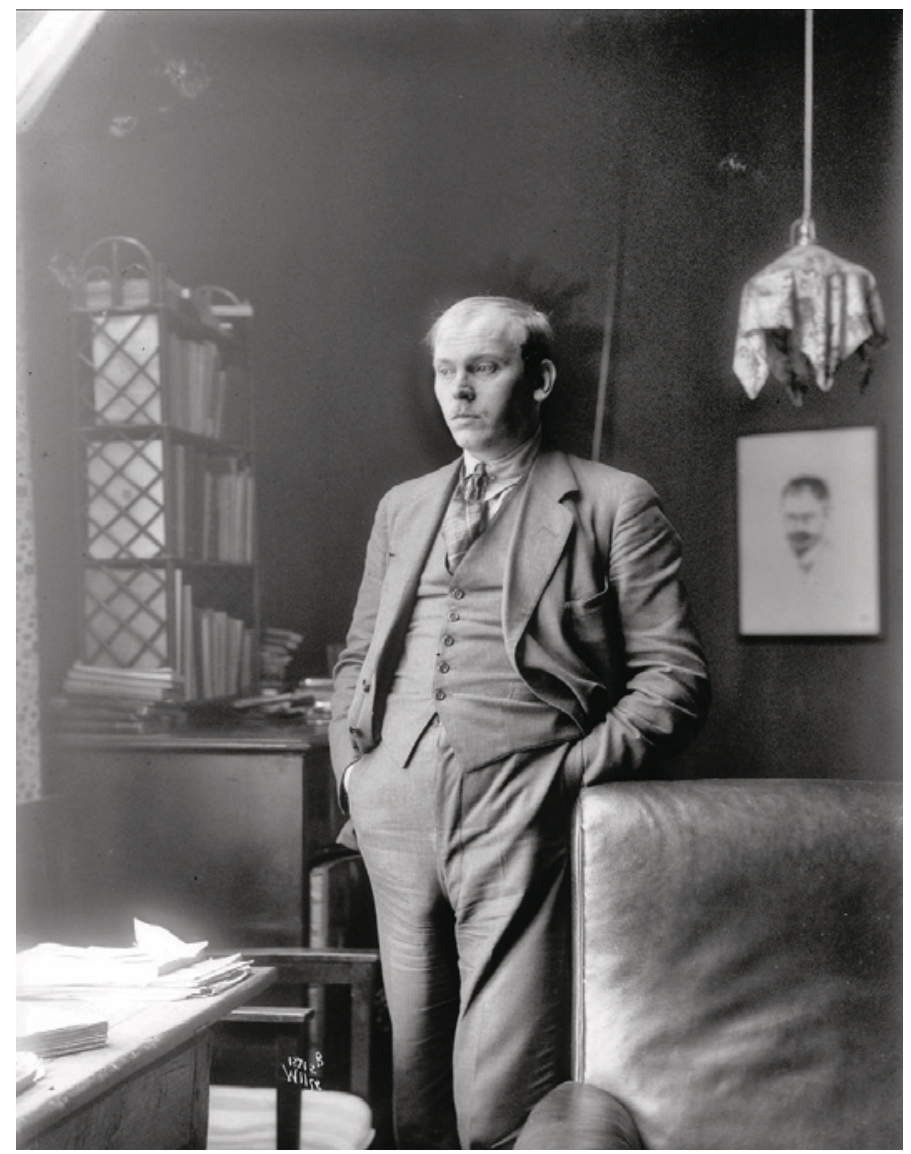

Olaf Jacob Martin Luther Bull, ca. 1920. Foto: Anders Beer Wilse/Oslo Museum (CC BY-SA)

derer med at å fange opp hint er «a key to building a trusting patient-physician relationship, thus ultimately improving outcome of care».

\section{Å lytte}

I samtalen i diktet ser vi at dikteren ikke bare tar hintet, men også responderer på det. Han spør «hvad tænker du paa?». Dette er et hva/hvordan-spørsmål om tanker og følelser. Slike spørsmål kan være meget potente - brukt følsomt i en terapeutisk samtale.

I Metope blir også dikterens direkte spørsmål om hennes/pasientens følelser et potent verktøy. Det utløser hennes monolog over fire strofer, hvor hun forteller om sin glede i nuet, sin angst for fremtiden og for døden. Man får inntrykk av at hun, gjennom å fortelle, modnes og nyanseres, hun går fra ren fortvilelse - «jeg ensom og angst og arm», «mon rædselens kveld er fjærn»til mer nyanserte følelser, «allikevel er det sødt og salig under», hvor hun også finner trøst i hans nærhet - «ta om meg, ven, og hold mig! Saan at trykkes er snart et eneste glimt av haab, jeg vet $-\gg$. Vi kan lese dette som at det å fortelle om sine tanker og følelser i seg selv virker modnende.

Hva er hans, dikterens (i vår lesning tera- peutens), rolle i hennes monolog? Jo, den er først og fremst å la henne snakke og å være til stede i hennes kommunikasjon, altså å lytte. Det første bud er da ikke å avbryte henne, men la henne snakke ferdig. Det gjør han. Hennes dialog tar om lag to minutter å lese høyt (egen måling). Pasientene snakker vanligvis ikke så lenge sammenhen-

\section{«Det er krevende å fange emosjonelle signaler»}

gende. I en studie med «vanskelige pasienter med komplekse historier» som fikk lov til å snakke uavbrutt, finner Langewitz og medarbeidere at pasientene i gjennomsnitt snakket i 92 sekunder (7). $78 \%$ av pasientene fullførte innen to minutter.

Dikteren klarer å lytte aktivt til hennes monolog. Hvordan er legers evne til det samme? Klarer leger flest å la pasienten snakke uavbrutt i to minutter uten å avbryte? Svaret på dette spørsmålet er nedslående. Beckmann og Frankel finner at legene i snitt avbryter pasienten 18 sekunder etter at de har stilt åpningsspørsmålet (8). Bare $23 \%$ av pasientene fikk lov til å fullføre sin åpningsmonolog. I bare én av 51 avbrutte monologer fikk pasienten lov til å komme tilbake til sitt utsagn senere i samtalen. $94 \%$ av alle avbrudd førte til at legen tok kontroll over samtalen.

Dikteren i Metope klarer altså noe leger flest ikke klarer: Å la samtalepartneren snakke uavbrutt.

Etter at kvinnen har snakket ferdig vender man i siste vers tilbake til mannen/dikteren, $\mathrm{i}$ vår lesning altså til terapeuten. $\mathrm{Vi}$ får ta del i hans tanker. Han er nå stilt overfor hennes dødsangst, et problem som ikke kan skjæres bort med kniv, eller drives tilbake med enkle pilleløsninger. Dette er likt det daglige arbeidet som kliniker i mange spesialiteter. Vi stilles ofte overfor pasienter som ikke kan forvente noen kur. I slike tilfeller får relasjonen til pasienten stor betydning (9). I Metope har dikteren/mannen, som vi har sett, allerede bygd opp en god relasjon gjennom å fange et emosjonelt signal, respondere på det, for så å lytte. Videre ser vi at han lever seg inn i hennes følelser: «Svimmel og sky fornemme, noget som bare er blikk og sind og stemme i smertelig angst og anelse løst opp». Han kan dog ikke helt ut identifisere seg med henne, han forblir Pan, der hvor hun er Psyke.

Men det er heller ikke nødvendig å dele en erfaring, eller å føle det samme, for å være empatisk. Derimot er det nødvendig å vise at man forstår pasientens følelser. Dikteren i Metope viser det gjennom kroppsspråk, «Alt jeg kan er stumt at stryke ditt duftige hår med hånden din i min». Ikke-verbal kommunikasjon kan være en sterk formidler av empati, og tilstrekkelig. Mange vil være engstelig for å vise støtte til pasienter med kroppsspråk, men studier viser at fysisk berøring $i$ allmennpraksis er ønsket av pasientene, og at de er mindre bekymret enn legen er for at det skal være invaderende (10). Uten direkte fysisk berøring vil også en interessert kroppsholdning og et rolig, fast blikk gi helt andre signaler enn hender på tastaturet og et raskt blikk ned på klokken. Dårlig blikkontakt kan alene være nok til å hindre åpen kommunikasjon $(11,12)$. Dersom ikke-verbal og verbal kommunikasjon gir motsatte signaler, vil ikke-verbal kommunikasjon tendere til å overkjøre de verbale utsagnene (13).

\section{$\AA ̊$ uttrykke empati}

I klinisk praksis vil det likevel ofte være ønskelig å uttrykke empati verbalt. Dette kan gjøres med setninger som inneholder et «jeg» og et «du», slik som: «Jeg forstår at det er skremmende for deg å tenke på døden». Å vise empati på denne måten bryter individets følelsesmessige isolasjon og 
er i seg selv terapeutisk. I en studie på kronisk hodepine med ett års oppfølgingstid var henvisninger, undersøkelser og behandling uten effekt på symptomlette, mens pasientens opplevelse av å ha blitt hørt, og av å ha fått diskutert problemet sitt fullt ut ga betydelig økt sjanse for full restitusjon (14). I en studie på vanlig forkjølelse ga opplevelse av empati fra legen redusert varighet og symptomtrykk (15). I en stor italiensk studie korrelerte høy empatiskår hos legen med færre metabolske komplikasjoner hos pasienter med diabetes (16). Ut fra dette er det et godt grunnlag for å mene at kvinnen i Metope oppnår symptomlette gjennom samtalen. Vi kan lese diktet som en effektiv, terapeutisk samtale.

Vi har sett at dikteren/mannen uttrykker empati. Man kan spørre seg om dette er noe leger klarer i sin kliniske praksis. Igjen må dessverre svaret bli nei. I en studie fra 2008 finner Morse og medarbeidere at thoraxkirurger og onkologer mister $90 \%$ av mulighetene til å vise empati i møtet med lungekreftpasienter (17). Tilsvarende er vist i forhold til pasienter som er hivsmittet (18).

Det kan virke skremmende med de refererte svake tallene for legers ferdigheter i den kliniske samtalen. Ett forhold er likevel oppmuntrende: Samtaleferdigheter kan læres, som andre ferdigheter. Dette gjelder alle aspekter ved pasientsamtalen som her er blitt diskutert (19). Det som skal til, er bevissthet og systematisk trening, som for andre kliniske ferdigheter.

\section{God klinisk samtale}

Jeg har i denne tolkningen av Metope som en terapeutisk samtale gitt diktet en optimistisk tolkning. Et kjærlighetsdikt om døds- angst kan ved å justere perspektivet leses som et vakkert eksempel på en god klinisk samtale. Vi ser hvordan terapeuten fanger opp emosjonelle signaler, responderer på dem, lytter og viser empati. Terapeuten bidrar med dette til trøst og lindring. Et av de mest verdsatte og elskede dikt i norsk litteratur kan tjene som inspirasjon for alle som ønsker å øve opp sine samtaleferdigheter.

Jeg takker kollega Henrik Brochmann for resitering av diktet høsten 1993 i Nærøy kommune under allmennmedisinsk utplassering, i tillegg til ektefelle Ingrid Habberstad for «walk and talk» i Bymarka våren 2015.

\section{Njål Flem Mæland (f. 1968)}

er fastlege ved Hallset legesenter, universitetslektor ved Norges teknisk-naturvitenskapelige universitet og rådgivende lege ved Nav SørTrøndelag.

Forfatter har fylt ut ICMJE-skjemaet og oppgir ingen interessekonflikter.

\section{Litteratur}

1. Norsk biografisk leksikon. Olaf Bull. https://nbl.snl.no/Olaf_Bull (25.4. 2016)

2. Wikipedia. Olaf Bull. https://nn.wikipedia.org/wiki/ Olaf_Bull (25.4.2016)

3. Jan Erik Vold. Det norske syndromet - et kritisk syn på norsk lyrikk. Oslo: Universitetsforlaget, 1980.

4. Levinson W, Gorawara-Bhat R, Lamb J. A study of patient clues and physician responses in primary care and surgical settings. JAMA 2000; 284 $1021-7$.

5. Zimmermann C, Del Piccolo L, Finset A. Cues and concerns by patients in medical consultations: a literature review. Psychol Bull 2007; 133: 438-63.

6. Tuckett D, Boulton M, Olson $C$ et al. Meetings between experts: an approach to sharing ideas in medical consultations. London: Tavistock, 1985.

7. Langewitz W, Denz M, Keller A et al. Spontaneous talking time at start of consultation in outpatient clinic: cohort study. BMJ 2002; 325: 682-3.

8. Beckman HB, Frankel RM. The effect of physician behavior on the collection of data. Ann Intern Med 1984; 101: 692-6.

9. Cocksedge S, Greenfield R, Nugent GK et al. Holding relationships in primary care: a qualitative exploration of doctors' and patients' perceptions. Br J Gen Pract 2011; 61: e484-91.

10. Cocksedge S, George B, Renwick S et al. Touch in primary care consultations: qualitative investigation of doctors' and patients' perceptions. $\mathrm{Br}$ J Gen Pract 2013; 63: e283-90.

11. Goodwin C. Conversation Organization: interaction between speakers and hearers. New York, NY: Academic Press, 1981.

12. Ruusuvuori J. Looking means listening: coordinating displays of engagement in doctor-patient interaction. Soc Sci Med 2001; 52: 1093-108.

13. McCroskey JC, Larson CE, Knapp ML. An introduction to interpersonal communication. Englewood Cliffs, NJ: Prentice Hall, 1971

14. The Headache Study Group of The University of Western Ontario. Predictors of outcome in headache patients presenting to family physicians - a one year prospective study. Headache 1986; 26: 285-94.

15. Rakel D, Barrett B, Zhang Z et al. Perception of empathy in the therapeutic encounter: effects on the common cold. Patient Educ Couns 2011; 85: $390-7$.

16. Del Canale S, Louis DZ, Maio V et al. The relationship between physician empathy and disease complications: an empirical study of primary care phy sicians and their diabetic patients in Parma, Italy. Acad Med 2012; 87: 1243-9.

17. Morse DS, Edwardsen EA, Gordon HS. Missed opportunities for interval empathy in lung cancer communication. Arch Intern Med 2008; 168: 1853-8.

18. Hsu I, Saha S, Korthuis PT et al. Providing support to patients in emotional encounters: a new perspective on missed empathic opportunities. Patient Educ Couns 2012; 88: 436-42.

19. Silverman J, Kurtz S, Draper J. Teaching and learning communication skills in medicine. Oxford: Radcliff Medical Press, 2004

Mottatt 19.7.2015 og godkjent 4.5.2016. Redaktør: Are Brean. 